\title{
MODEL PELESTARIAN LINGKUNGAN HIDUP BERBASIS TEKNOLOGI INFORMASI PADA AKTIVITAS SOSIALISASI BERBASIS MASYARAKAT SEBAGAI SENTRA PARTISIPAN
}

\author{
Wahyu Sardjono \\ Jurusan Sistem Informasi, Fakultas Ilmu Komputer, Binus University \\ Jl. KH. Syahdan No. 9, Palmerah, Jakarta Barat 11480. \\ sul354@yahoo.co.id
}

\begin{abstract}
The environment is a gift and grace of the Almighty God to man as home to life. In utilizing natural resources to promote human welfare, a sustainable environmental development should be carried out, which cares about the needs of present and future generations. On the other hand, the development of information and communication technology (ICT) grows so fast that can change the way people live and work. Collaboration between the environment and its preservation with ICT knowledge can be developed into an environmental knowledge and management system (E-KMS). An approach to efficiency and effectiveness in ICT which includes variables of timing, capacity, relevance, accessibility, flexibility, accuracy and reliability can be used to explore the determinants of the success of the socialization of community-based environmental conservation as a central participant. The multivariate statistical methods and factor analysis can produce new variables declared as an indicator of research results and model testing.
\end{abstract}

Keywords: conservation, environment, environmental knowledge management systems (E-KMS)

\begin{abstract}
ABSTRAK
Lingkungan hidup adalah karunia dan rahmat Tuhan Yang Maha Esa kepada manusia serta merupakan tempat tinggal bagi kehidupan. Dalam memanfaatkan sumberdaya alam untuk memajukan kesejahteraan manusia, perlu dilakukan pembangunan berkelanjutan berwawasan lingkungan, dengan memperhitungkan kebutuhan generasi masa kini dan masa depan. Pada sisi lain, perkembangan teknologi informasi dan komunikasi atau information and communication technology (ICT) berkembang sangat cepat dan mampu mengubah cara hidup dan cara kerja manusia. Kolaborasi antara pengetahuan lingkungan hidup dan pelestariannya dengan pengetahuan ICT dapat dikembangkan menjadi sistem pengelolaan dan pengetahuan lingkungan atau environmental knowledge management systems (E-KMS). Pendekatan efisiensi dan keefektifan pada ICT yang meliputi variabel ketepatan waktu, kapasitas, relevansi, aksesabilitas, fleksibilitas, akurasi dan realibilitas dapat dipakai untuk mengeksplorasi faktor-faktor penentu keberhasilan sosialisasi pelestarian lingkungan hidup berbasis masyarakat sebagai sentra partisipan. Dengan metode statistik multivariate dan analisis faktor dapat dihasilkan variabel baru yang dinyatakan sebagai indikator hasil penelitian dan pengujian model.
\end{abstract}

Kata kunci: pelestarian, lingkungan hidup,environmental knowledge management systems (E-KMS) 


\section{PENDAHULUAN}

Lingkungan Hidup menjadi bagian yang tak terpisahkan dari dinamika kehidupan masyarakat dan selalu terkait dengan kegiatan pembangunan yang telah, sedang dan akan dilaksanakan. Isu-isu lingkungan hidup menjadi semakin santer dewasa ini baik ditingkat lokal, regional, maupun nasional seperti pencemaran sungai, polusi udara, kerusakan lautan, terumbu karang dan sumber daya lainnya.

Perhatian terhadap langkah-langkah pengembangan pendidikan lingkungan hidup pada beberapa tahun terakhir ini semakin meningkat, baik untuk pendidikan sekolah dan pendidikan luar sekolah. Namun, harus diakui bahwa masih banyak hal yang perlu terus selalu diperbaiki agar pendidikan lingkungan hidup dapat lebih memasyarakat secara konsisten dan berkelanjutan. Dengan demikian, kegiatan sosialisasi lingkungan hidup yang dilaksanakan melalui berbagai bentuk kegiatan dapat memberikan hasil yang optimal.

\section{METODE}

Merancang pengembangan model sosialisasi diawali dengan melakukan analisis kebutuhan sosialisai pelestarian lingkungan hidup dan prioritasnya pada lembaga terkait, selanjutnya melakukan identifikasi masalah yang ada dan diakhiri dengan melakukan pembandingan dan evaluasi tentang apakah yang ada saat ini telah sesuai dengan yang seharusnya dilakukan. Pendekatan penelitian ini menggunakan model penelitian eksplorasi (exploratory research). Hasil analisis tersebut selanjutnya dipergunakan untuk menyusun model dan merancang penelitian.

Pada fase ini akan dihasilkan analisis tentang Knowledge Goal yang akan didapatkan, dan akan diuraikan ke dalam proses inti dari pengelolaan pengetahuan (Core Process of KM), yang terdiri dari: (1) knowledge identification, (2) knowledge acquisition, (3) knowledge development, (4) knowledge sharing and distribution, (5) knowledge utilization, (6) knowledge retention.

Selanjutnya proses evaluasi atau pengukuran tentang sistem pengelolaan pengetahuan yang dibangun dilakukan dengan menggunakan IT Balanced Scorecard melalui empat perspektif, yaitu: (1) government contribution, (2) society orientation, (3) operation excellent, (4) future orientation.

\section{HASIL DAN PEMBAHASAN}

\section{Terminologi Lingkungan Hidup}

Lingkungan Hidup adalah kesatuan ruang dengan semua benda, daya, keadaan, dan makhluk hidup termasuk manusia dan perilakunya yang mempengaruhi kelangsungan prikehidupan dan kesejahteraan manusia serta makhluk hidup lainnya. Pengelolaan Lingkungan Hidup adalah upaya terpadu untuk melestarikan fungsi lingkungan hidup yang meliputi kebijaksanaan penataan, pemanfaatan, pengembangan, pemeliharaan, pemulihan, pengawasan dan pengendalian lingkungan hidup (Amron, 2007).

\section{Perkembangan Pendidikan Lingkungan Hidup di Tingkat Internasional}

Pada tahun 1975, sebuah lokakarya internasional tentang pendidikan lingkungan hidup diadakan di Beograd, Jugoslavia. Pada pertemuan tersebut dihasilkan pernyataan antar negara peserta 
mengenai pendidikan lingkungan hidup yang dikenal sebagai "The Belgrade Charter - a Global Framework for Environmental Education" (situs Kementrian Lingkungan Hidup).

Secara ringkas tujuan pendidikan lingkungan hidup yang dirumuskan dalam Belgrade Charter tersebut di atas adalah sebagai berikut: (1) Meningkatkan kesadaran dan perhatian terhadap keterkaitan bidang ekonomi, sosial, politik serta ekologi, baik di daerah perkotaan maupun pedesaan; (2) Memberi kesempatan bagi setiap orang untuk mendapatkan pengetahuan, keterampilan, sikap/perilaku, motivasi dan komitmen, yang diperlukan untuk bekerja secara individu dan kolektif untuk menyelesaikan masalah lingkungan saat ini dan mencegah munculnya masalah baru; (3) Menciptakan satu kesatuan pola tingkah laku baru bagi individu, kelompok-kelompok dan masyarakat terhadap lingkungan hidup.

\section{Perkembangan Pendidikan Lingkungan Hidup di Tingkat Indonesia}

Memorandum Bersama antara Departemen Pendidikan dan Kebudayaan dengan Kementerian Negara Lingkungan Hidup No. 0142/U/1996 dan No Kep: 89/MENLH/5/1996 tanggal 21 Mei 1996 membahas tentang Pembinaan dan Pengembangan Pendidikan Lingkungan Hidup. Sejalan dengan itu, Direktorat Jenderal Pendidikan Dasar dan Menengah (Dikdasmen) Departemen P\&K juga terus mendorong pengembangan dan pemantapan pelaksanaan pendidikan lingkungan hidup di sekolahsekolah antara lain melalui penataran guru, penggalakkan Bulan Bakti Lingkungan, penyiapan Buku Pedoman Pelaksanaan Pendidikan Kependudukan dan Lingkungan Hidup (PKLH) untuk Guru SD, SLTP, SMU dan SMK , program sekolah asri, dan lain-lain. Selain itu, berbagai insiatif dilakukan baik oleh pemerintah, LSM, maupun perguruan tinggi dalam mengembangkan pendidikan lingkungan hidup melalui kegiatan seminar, sararasehan, lokakarya, penataran guru, pengembangan sarana pendidikan seperti penyusunan modul-modul integrasi, buku-buku bacaan dan lain-lain.

\section{Perkembangan e-Learning Systems}

Seiring dengan perkembangan teknologi informasi (TI) yang semakin pesat, kebutuhan akan suatu konsep dan mekanisme belajar mengajar (pendidikan) berbasis TI menjadi tidak terelakkan lagi. Konsep yang kemudian terkenal dengan sebutan e-Learning ini membawa pengaruh terjadinya proses transformasi pendidikan konvensional ke dalam bentuk digital, baik secara isi (content) dan sistemnya.

Saat ini konsep e-Learning sudah banyak diterima oleh masyarakat dunia, terbukti dengan maraknya implementasi e-Learning di lembaga pendidikan (sekolah, training dan universitas) maupun industri (Cisco System, IBM, HP, Oracle, dsb). John Chambers yang merupakan CEO dari perusahaan Cisco System mengatakan bahwa untuk era ke depan, aplikasi dalam dunia pendidikan akan menjadi "killer application" yang sangat berpengaruh. Departemen perdagangan dan departemen pendidikan Amerika Serikat bahkan bersama-sama mencanangkan Visi 2020 berhubungan dengan konsep pendidikan berbasis teknologi informasi (e-Learning) (Vision, 2002).

\section{Pengembangan lingkungan hidup berkesinambungan}

Interpretasi dari pendidikan berkesinambungan yg menghubungkan antara teori dengan domain afektif/praktis seperti nilai, sikap dan perilaku (Shephard, 2007) dalam ruang lingkup lingkungan hidup dapat dipakai sebagai contoh yang jelas bagaimana teori dan pengalaman yang relevan bisa dikelola menjadi suatu manfaat untuk pendidikan berkelanjutan.

Kesinambungan merupakan kata kunci bagi pengelola lingkungan hidup dalam pengertian dan pemanfaatan potensi lebih dari keunggulan sistem dan teknologi informasi untuk program lingkungan hidup lebih efektif (Box, 2002). Dan implikasi sistem dan teknologi informasi ini juga berdampak pada hubungan sosial serta ekonomi informasi yang sangat berguna bagi generasi penerus dalam kerangka kearifan budaya (Fuchs, 2008). 
Kemajuan sistem dan teknologi informasi membawa pengaruh perubahan sosial dan memberikan imbas penting pada kemajuan ekonomis, sosial dan area lingkungan dan selanjutnya akan berimbas pula pada kesinambungan ekonomi social (Casal et al., 2005), eksplorasi mendalam secara kualitatif dan kemampuan akses kuantitatif dari sistem dan teknologi informasi akan mendorong dan mempengaruhi lingkungan hidup menuju peluang dan tantangan tahu masa depan (Institute for Prospective Technological Studies (IPTS), 2004).

Penilaian aspek terkait dengan pengembangan berkesinambungan meliputi ketersediaan informasi dan standarisasi lingkungan dari aspek dan kriteria sosial perlu dimasukkan dalam kerangka kerja (framework) pengelolaan siklus hidup implementasi sistem pada setiap komunitas (Brent, 2007).

Dari sejumlah literatur diatas - terkait dengan masalah lingkungan hidup, sistem komunikasi dan teknologi informasi atau information and communication technology (ICT), dan pengembangan berkesinambungan - kolaborasi di antara ketiganya dapat dimanfaatkan dan dimaksimalkan untuk mendukung program pelestarian lingkungan hidup termasuk di dalamnya adalah aktifitas sosialisasi seperti yang selama ini telah dilakukan dengan baik. Meski masih searah dari fasilitator ke masyarakat/publik/partisipan ('facilitator centric'), cara yang pada umumnya belum menempatkan masyarakat/publik/partisipan sebagai pusat ('participant centric'), dimana pada konsep ini diharapkan partisipan berperan aktif dan fasilitator menjadi salah satu referensi dari sejumlah referensi yang ada (fasilitator tidak hanya menjadi satu-satunya nara sumber). Penelitian ini akan membangun metodologi pelestarian lingkungan hidup dengan memanfaatkan ICT pada aktifitas sosialisasi dengan konsep 'participant centric'.

\section{PENUTUP}

Adapun kesimpulan yang dapat diambil yaitu: (1) Pemilihan tools untuk uji coba, pengembangan sistem, pengembangan content, kontrol indikator keberhasilan sosialisasi mandiri (self assessment); (2) Membangun prototype sistem dengan melaksanakan implementasi model yang telah dibuat pada institusi/lembaga/industri yang terpilih dan membuat rencana pengukuran kinerja sesuai sistem serta rancangan penentuan KPI's dan KGI's; (3) Merancang model evaluasi dari perspektif teori, implementasi dan regulasi; (4) Mengambil data primer dan mengolah data serta menganalisis data dengan teknik Factor Analysis dari multivariate statistic, yaitu mencari kontribusi positif penggunaan metodologi yang telah dibuat terhadap proses implementasi sistem pada institusi/lembaga/industri dan masyarakat terpilih yang terjadi karena adanya model sosialisasi yang bisa dilakukan secara mandiri dan terukur.

\section{DAFTAR PUSTAKA}

Amron. (2007). Kajian Lingkungan Hidup dalam Pembangunan Wilayah dalam Konteks Pembangunan Infra Struktur Pekerjaan. Dipresentasikan pada Seminar Nasional Pembangunan Wilayah Berbasis Lingkungan di Indonesia, Yogyakarta.

Box, W. J. (2002). Sustainability is IT, Pollution Engineering. Proquest Journal.

Brent, A. C. \& Labuschagne, C. (2007). An Appraisal of Social Aspects in Project and Technology Life Cycle Management in the Process Industry, 18 (04), pp. 413-426. Bingley, UK: Emerald Group Publishing. 
Casal, C. R., Wunnik, C.V., Sancho, L. D., Claud, Jean. (2005). How will ICTs Affect Our Environment in 2020?. Foresight: The Journal of Futures Studies, Strategic Thinking and Policy, 7 (01), 77.

Fuchs, Christian. (2008). The Implications of New Information and Communication Technologies for Sustainability, Environment, Development and Sustainability, 10. (03), 291.

Institute for Prospective Technological Studies (IPTS). (2004). The Future Impact of ICTs on Environmental Sustainability. Seville: Erdmann, L., Hilty, L., Goodman, J. \& Arnfalk, P.

Shephard, Kerry. (2007). Higher Education for Sustainability: Seeking Affective Learning. Diakses dari

http://www.slu.edu/Documents/sustainability/higher\%20education\%20for\%20sustainability\% 20-\%20seeking\%20affective\%20learning\%20outcomes\%280\%29.pdf

U.S. Department of Commerce Technology Administration. (2002). Vision 2020: Transforming Education and Training through Advanced Technologies. Washington D.C.: Ruzena Bajcsy. Retrieved from http://www.technology.gov/reports/TechPolicy/2020Visions.pdf. 